\title{
Implementation of ergonomics in design practice: outline of am approach and some discussion points
}

\author{
R. N. PikaAR, T. M. J. Lenior and J. E. RiJnsDorP \\ Ergonomics Group, University of Twente, P.O. Box 217, \\ 7500 AE Enschede, The Netherlands \\ ErgoS, Ergonomical Systems Engineering, P.O. Box 545, \\ 7500 AM Enschede, The Netherlands
}

\section{Introduction}

Designing man-machine systems within the scope of large-scale automation projects is, as a rule, a complicated matter. In many projects, attention is not given to ergonomic aspects until the detailed engineering stage. It then concerns such aspects as the outfitting of a workstation and environmental factors. For instance, this attention might very well be caused by problems expected from the use of visual display units or anthropometric issues such as the right chair to choose. There are still relatively few people who know that ergonomics is about more than workplace and man-machine interface design.

An ergonomic contribution to earlier design phases, during which, amongst other things, jobs are defined, is not yet common practice. If an ergonomist is involved in a project he/she has to compromise in view of limited budgets, project deadlines, technical constraints and, last but not least, a lack of recognition and acceptance of a human-factors input during design and engineering. To get ergonomics accepted as part of a project there are in most cases two conditions which have to be met:

(1) the benefits of an investment in ergonomic analyses, consultation and realizing user participation has to be shown beforehand; and

(2) the ergonomic contribution must fit the project procedures.

As it is a main topic of this conference, the former condition is discussed in many papers. The latter condition is the issue of this cluster of papers. A lot of different approaches, design methodologies or whatever name is used, have been published in the ergonomic literature. The approach which is outlined here has been practiced by the authors and colleagues for many years; for more details see Mulder (1980), Lenior et al. (1980), Rijnsdorp et al. (1983) and Pikaar et al. (1985). The reason for presenting an outline of this approach is to show an example which could be integrated in many existing company design and engineering procedures. It is also illustrative because the approach is used in three of the other papers in part VII of the proceedings.

\section{Ergonomic systems design}

In spite of the differences between the objectives of available/applied design procedures, the basic structure is always very similar. All procedures consist of a number of phases which should be executed in a sequence. After some sort of feasibility study, the design procedures contain four phases in common. The first one is a definition of the design problem. After an analysis of the design problem in the second phase, the third 
phase is devoted to the development of solutions. The fourth phase involves the detailed design and implementation. In addition, it should be noted that some form of iteration is unavoidable.

The approach to systems design, outlined in this paper, is based on the theoretical framework offered by system ergonomics (Singleton 1974). A system is defined as a User(s)-Machine(s)-System (referred to as UMS).

The general project structure of applying the approach is shown in figure 1 (see also Pikaar 1986). The essential steps are problem definition, situation analysis, task allocation and detailed engineering. The essential steps in this approach are described below.

\subsection{Problem-definition phase}

The problem-definition phase starts with a general orientation on the project and the purpose of the system to be designed. General knowledge on the future UMS is collected. Outlines of subsequent design steps have to be negotiated with project management. This includes system boundaries and general design constraints as well as the extent and type of user participation, and the responsibilities of the ergonomists within the project.

\subsection{Situation analysis}

A situation analysis is a combination of a formal specification of the UMS and a task analysis in the existing situation. The purpose of a situation analysis is to gain insight into existing and future UMS tasks, regardless of an allocation of system tasks. This insight should be as effective as possible under given real-time circumstances. In addition, a study on the future use of the UMS must be carried out, taking account of system boundaries, general design requirements and constraints.

Several analysis techniques are available. The specific choice of technique depends on the type of industry and jobs to be analysed. One should merely fill in the general structure of a situation analysis with (known) appropriate techniques. The general structure is as follows.

(1) System specification: specification of instruments, workplace layout, jobs and organizational structure, formal job descriptions and so on.

(2) Task analysis, consisting of objective measurements (such as observations) and subjective measurements (such as interviews).

\subsection{Allocation of system tasks}

An allocation of system tasks is explicitly carried out to determine the number and type of tasks to be performed by human operators and the technical part of the system. In most projects this allocation is the ergonomic contribution to the functional analysis in which the degree and type of automation is specified. As a result, the new operator jobs and the work organization are established (Rijnsdorp et al. 1984). The allocation phase mostly leads to various alternative possibilities to realize the system. Then, together with the users, one of the alternatives can be chosen. A mock-up is often used as an aid to visualizing the design alternatives.

\subsection{Detailed engineering phase}

For detailed engineering several choices have to be made, weighting all the factors involved, including ergonomics. User participation offers the possibility of supporting 


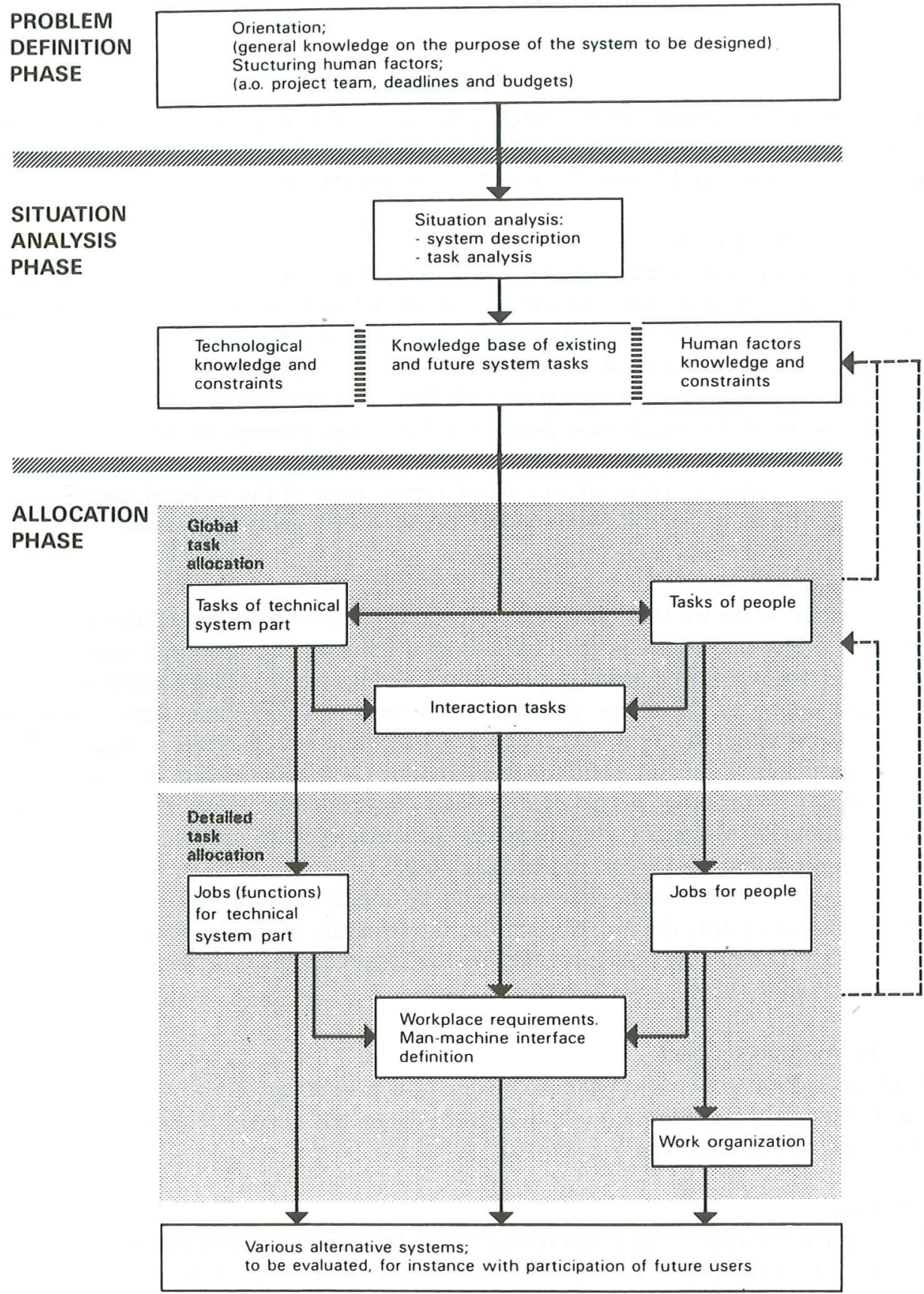

Figure 1. General project structure for system design from an ergonomic point of view. 
this decision-making process. Finally, workplaces, environment, etc., are engineered. Though not always in use by engineers, there is an extensive knowledge base available for workplace and man-machine interaction design, for instance in handbooks by Salvendy (1987) and Helander (1988).

\section{Discussion}

Implementation of ergonomics in design practice is not a simple matter. In each project many problems must be solved. We will mention three subjects which will be discussed in the next papers and follow these with some remarks about cases.

\subsection{User participation}

During all the phases mentioned above systematic consultation of all persons involved in the system to be designed is valuable. Experienced users/workers within a UMS can offer valuable contributions to the design of workplaces. They dispose of a wide and detailed knowledge of a production process and have practical experience that is not documented or known to designers or staff. The main problem is to find efficient and effective ways of involving these persons in the design process. In addition, there is generally a problem of 'selling' the idea of user participation to management and designers, in order to create attention and appreciation of the value of ideas of nondesigners. In one of the following papers Brown (1990) gives an excellent overview.

\section{2. 'Design behaviour'}

It can easily be shown that designers' behaviour conflicts with procedures in several respects. Most important is the contradiction between the thorough analysis and definition that is required in design procedures, and the way in which designers develop their perception of the design problem. They tend to verify their ideas of possible solutions, although in a rational procedure falsification and iteration is required. This seems particularly difficult when the work requires a certain amount of creativity. In this sense prescribing a detailed design methodology can even be called 'unergonomical'. Mossink (1990) discusses this issue. Background information can be found in the paper by Lenior and Mossink (1988).

Knowledge about design behaviour must be implemented, as design methodology encompasses not only the process but also the structure of the design system. This is particularly true for CAD systems which try to support designers in planning the design process (Pikaar 1989).

\subsection{Project management}

There is no doubt that project management is crucial to the possibility of implementing ergonomics, with or without methodology. In the second cluster of papers of Part VII this topic will be thoroughly discussed.

\subsection{Cases}

The approach to ergonomic system design described here has functioned well in several projects. An example of a large project is the Esso FLEXICOKER project. The application of the approach in this project was very important for the development of the method. Details of the ergonomic contributions are given in Pikaar et al. (1985). In the following paper (Pikaar et al. 1990) the project is being discussed by the project manager, a user representative, an interior architect and an ergonomist. 
From experience with this approach and with other ergonomic design methodologies one must conclude that every project is different. A general method for tackling the problems is not available. For each case one should carefully decide on the (ergonomic oriented) activities during the project.

\section{References}

BRowN, O. 1990, Marketing participatory ergonomics: current trends and methods to enhance organizational effectiveness, Ergonomics, 33, 601-604.

Helander, M. (ed.), 1988, Handbook of Human-Computer Interaction (Elsevier, Amsterdam).

Lenior, T. M. J. and Mossink, J. C. M. 1988, Do design procedures fit designers' behaviour? Proceedings 3rd IFAC/IFIP/IFORS/IEA Conference on Analysis, Design and Evaluation of Man-Machine Systems, Oulu, Finland (Pergamon Press, Oxford).

Lenior, T. M. J., RijnsDorp, J. E. and Verhagen, L. H. J. M. 1980, From field operators tp central control room operators, an integrated educational, research and consultancy approach, Ergonomics, 23, 741.

MuldER, H. F. 1980, Ergonomie-Een mensvriendelijke technologie, Natuur en Techniek, 48, 2 (in Dutch).

Mossink, J. C. M. 1990, Evaluation of design practice and the implementation of ergonomics, Ergonomics, 33, 613-619.

PIKAAR, R. N. 1986, Man-machine interaction in process control; a state-of-the-art report, in Willumeit, H.-P. (ed.) Human Decision Making and Manual Control, 5th European Annual Manual (North-Holland, Amsterdam).

PIKAAR, R. N. 1989, Situation analysis of design tasks for CAD systems, Behaviour and Information Technology, 8, 191-206.

PikAAR, R. N., LENIOR, T. M. J. and RiJnsDorP, J. E. 1985, Control room design from situation analysis to final layout; operator contributions and the role of ergonomists, in Johannsen, G., Mancini, G. and Martensson, L. Second IF AC/IFIP/IFORS/IEA Conference on Analysis, Design and Evaluation of Man-Machine Systems (Pergamon Press, Oxford).

Pikaar, R. N., Thomassen, P. A. J., Degeling, P. and Van Andel, H. 1990, Ergonomics in control room design, Ergonomics, 33, 589-600.

RiJnsDorP, J. E., PikAaR, R. N. and LenIOR, T. M. J. 1983, An interdisciplinary design approach for process control, Proceedings International Research Symposium 'New Techniques and Ergonomics', Valenciennes, France.

Rijnsdorp, J. E., PIKAar, R. N. and Lenior, T. M. J. 1984, Process control and Organization, in Proceedings of the Ninth IF AC World Congress (Pergamon, London).

Salvendy, G (ed.). 1987, Handbook of Human Factors (Wiley, New York).

Singleton, W. T. 1974, Man-Machine Systems (Penguin, London). 